Supplement of Biogeosciences, 15, 137-157, 2018

https://doi.org/10.5194/bg-15-137-2018-supplement

(C) Author(s) 2018. This work is distributed under

the Creative Commons Attribution 3.0 License.

(c) (1)

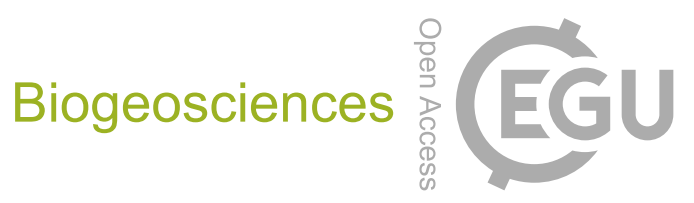

Supplement of

\title{
Microbial methanogenesis in the sulfate-reducing zone of sediments in the Eckernförde Bay, SW Baltic Sea
}

Johanna Maltby et al.

Correspondence to: Johanna Maltby (jmaltby@sjcme.edu) and Tina Treude (ttreude@g.ucla.edu)

The copyright of individual parts of the supplement might differ from the CC BY 3.0 License. 


\section{Supplement}

2 Figure S1: Development of sediment methane concentrations in net methanogenesis experiments at

3 different depths in March 2013 (A), June 2013 (B), September 2013 (C), November 2013 (D), March

$42014(E)$, June 2014 (F), and September 2014 (G). Shown are measurements in triplicates (a, b, c) with

5 trendline and slope for each replicate. $\mathrm{Y}$-axis shows the methane concentration in $\mu \mathrm{M}$, and $\mathrm{x}$-axis

6 shows the time in days.

7 A
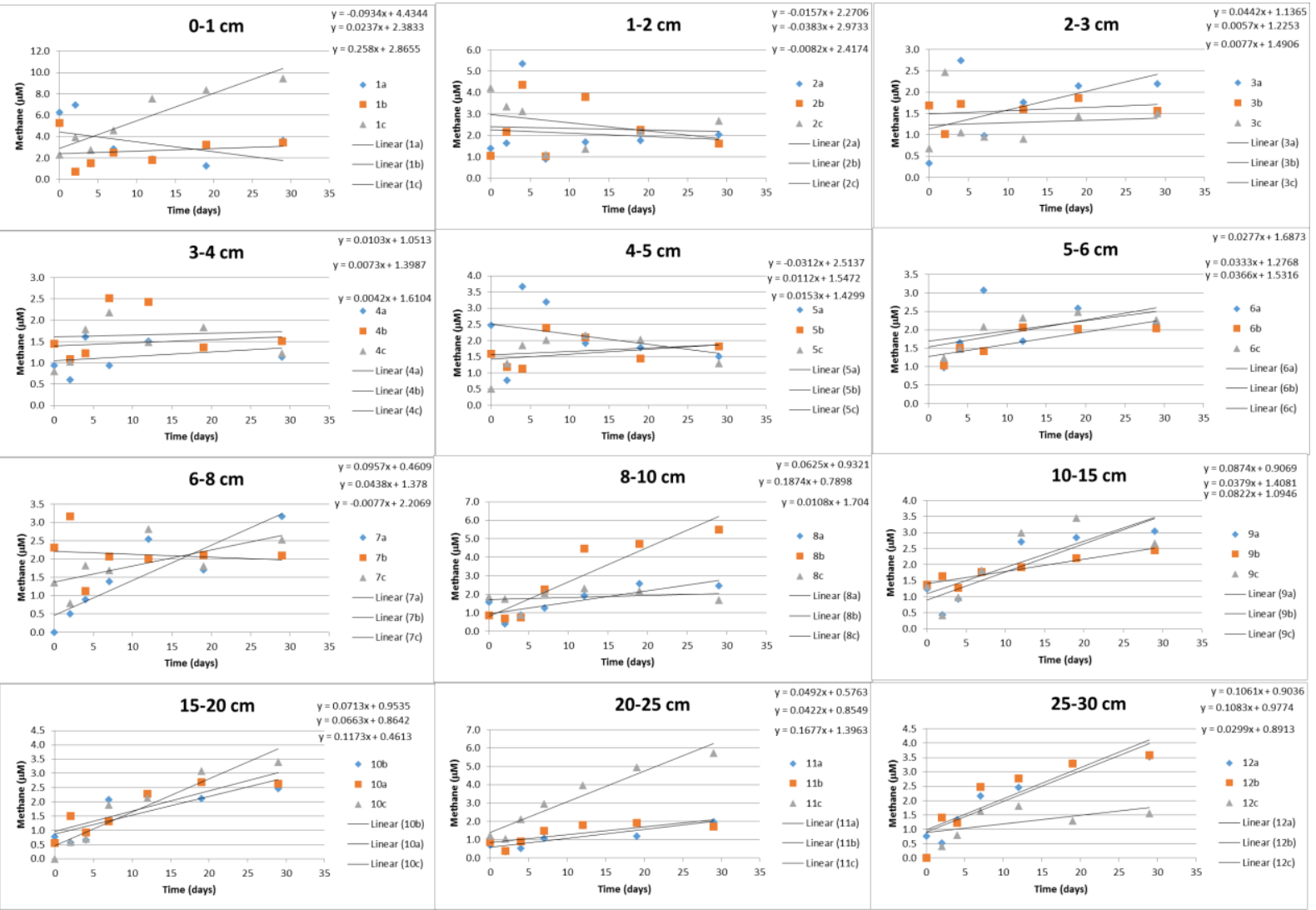

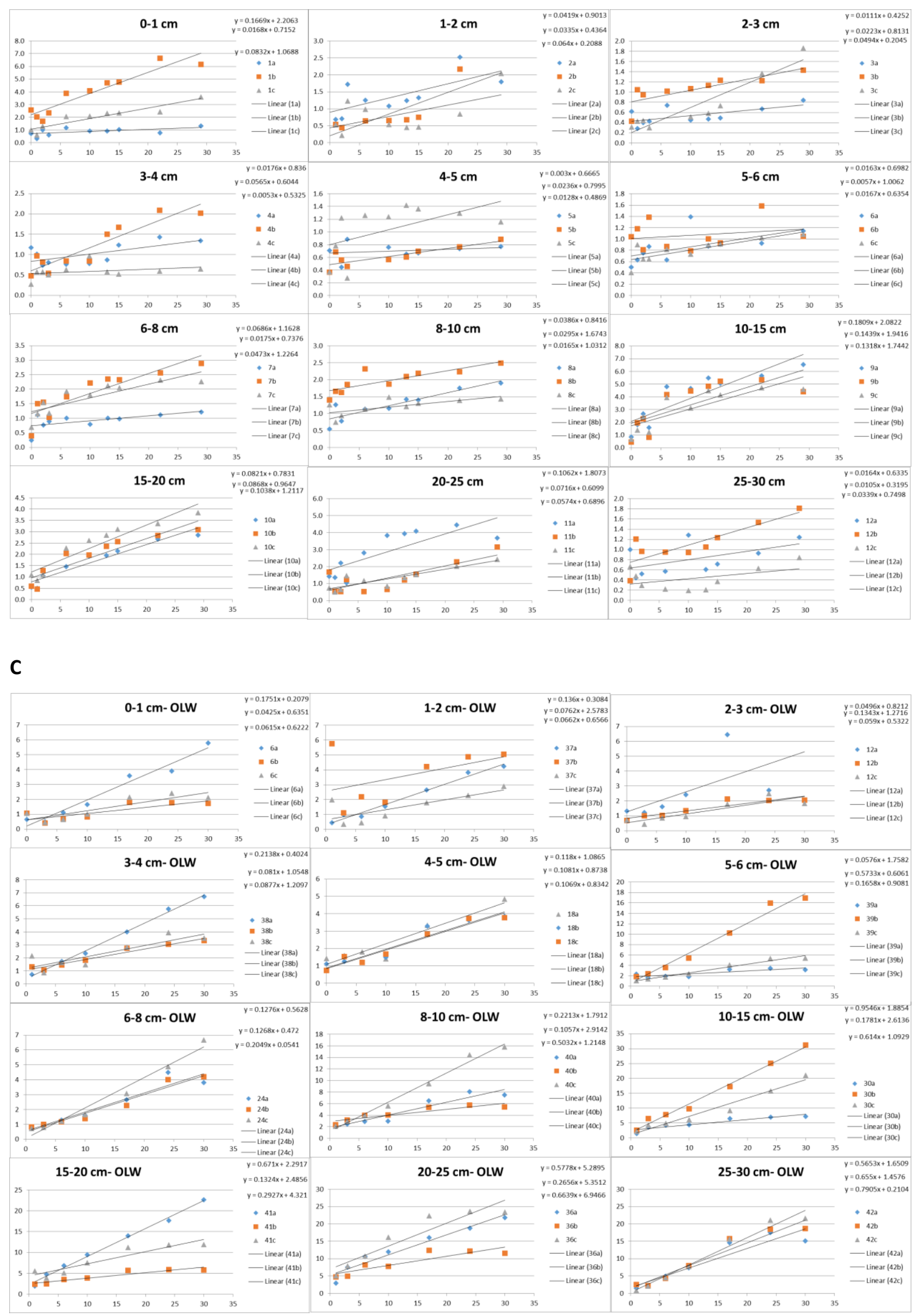


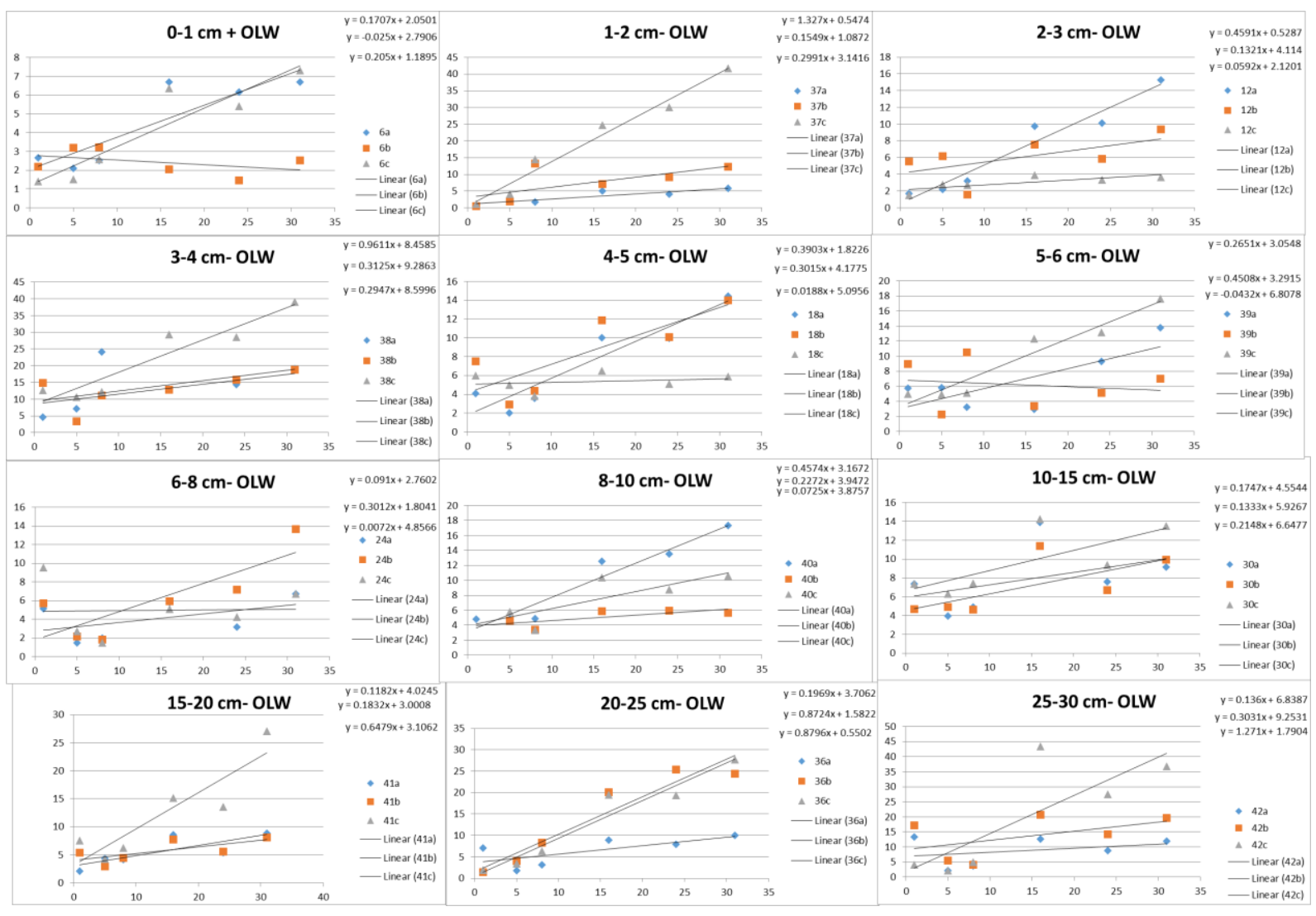

24 E

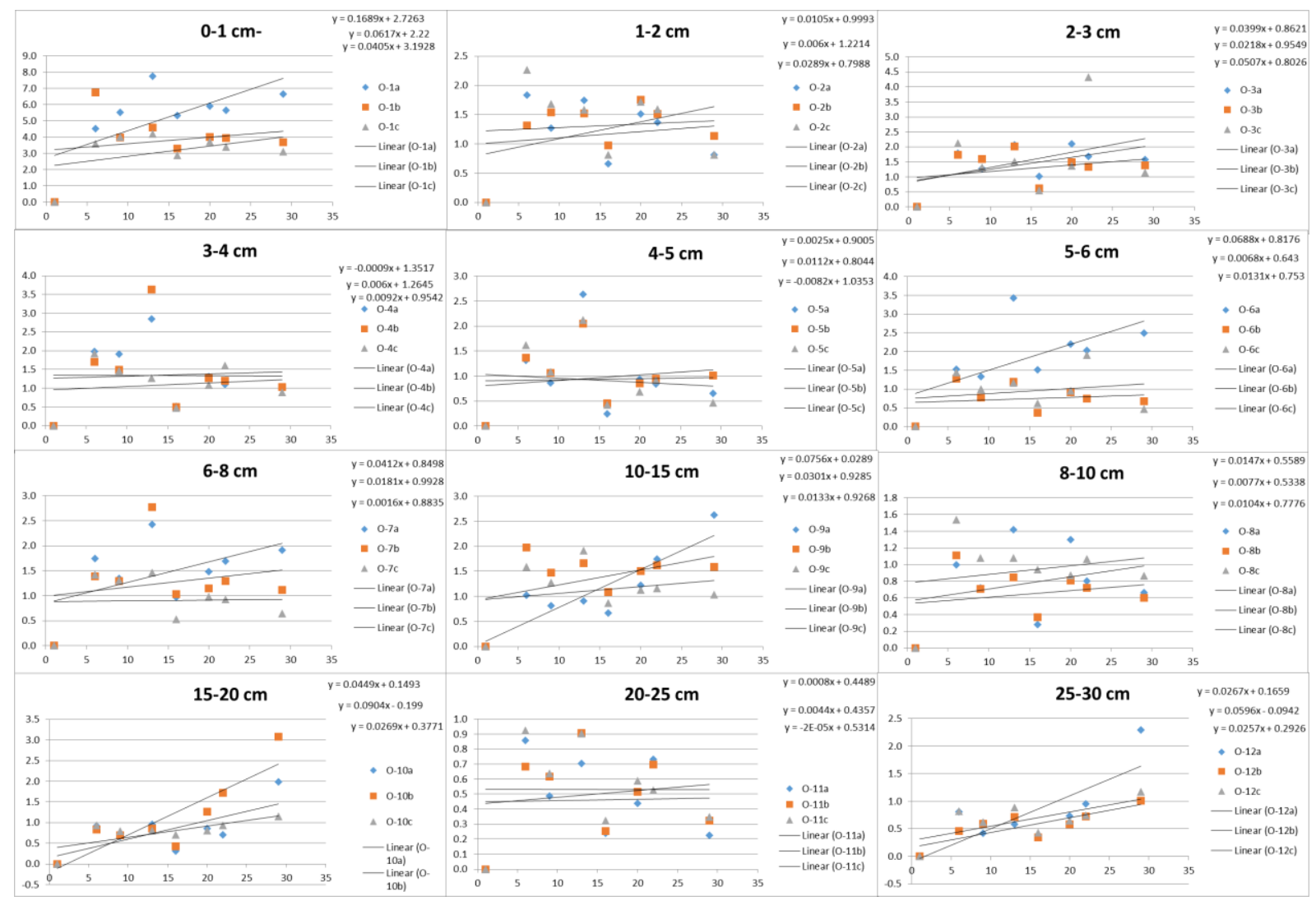




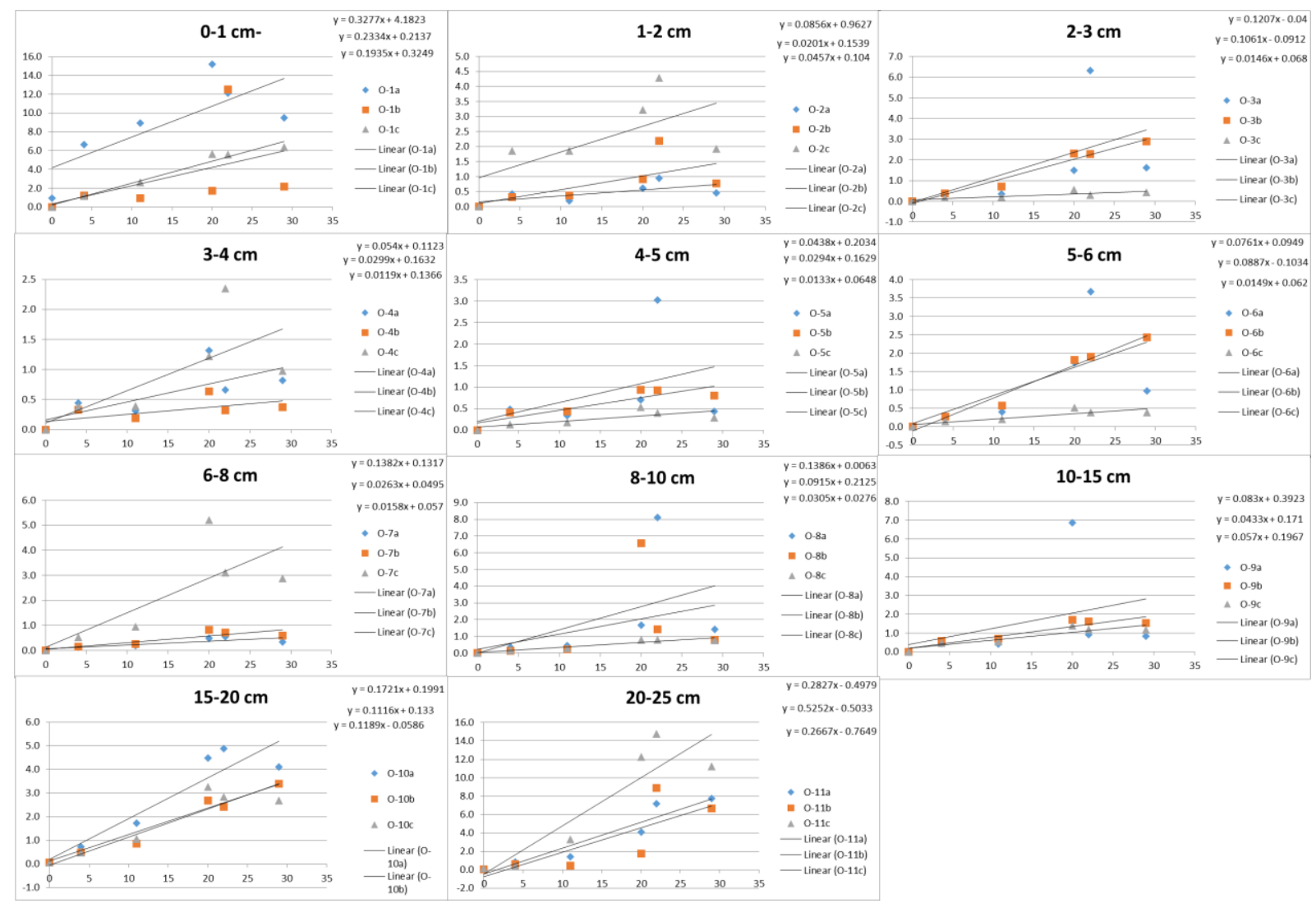

29

G

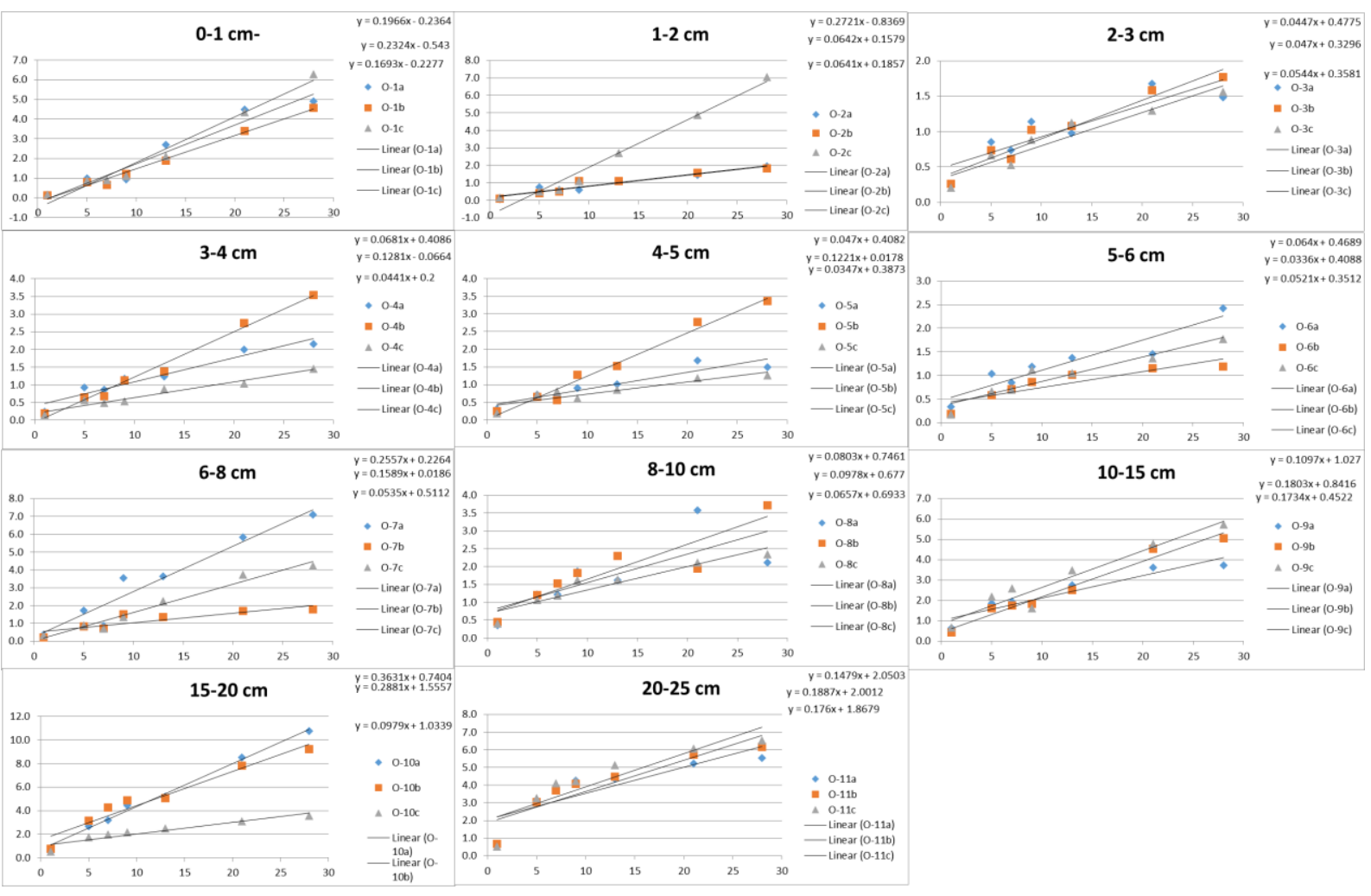


32 Figure S2: Example for the sediment methane increase in triplicates after addition of methanol

33 (=methanol treatment) in March 2014. Methane showed a similar development at the other three 34 time points November 2013, June 2014 and September 2014 (data not shown).

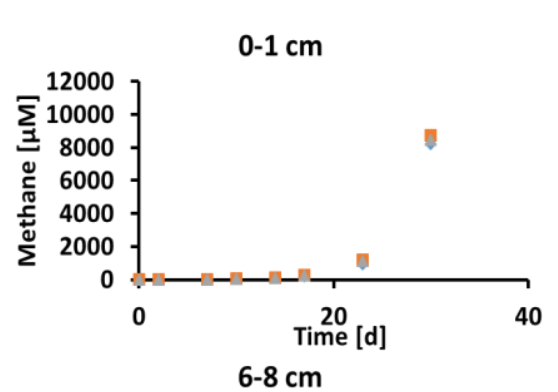

March 2014-Methanol treatment

$2-3 \mathrm{~cm}$

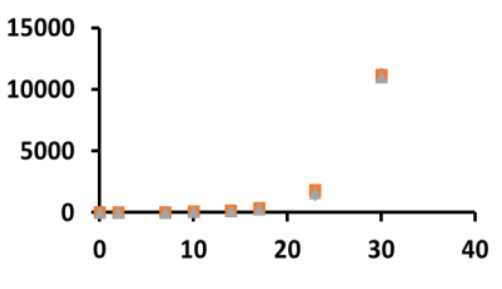

$10-15 \mathrm{~cm}$

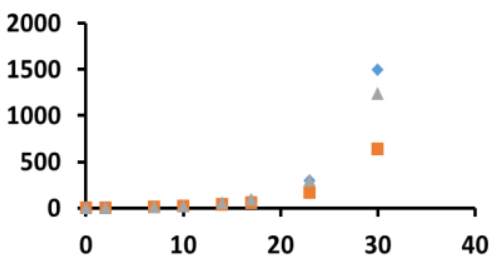

4-5 cm
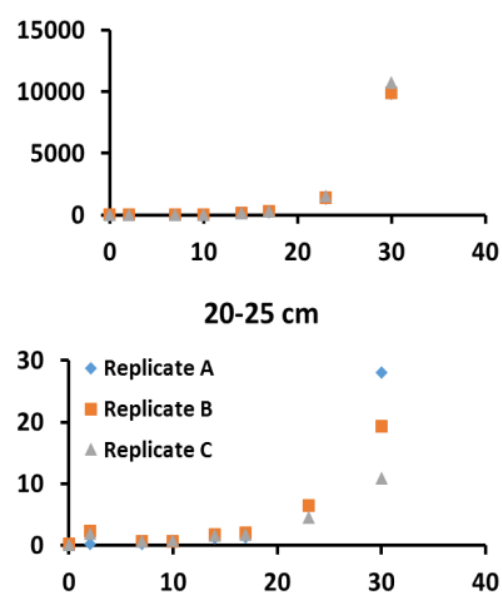

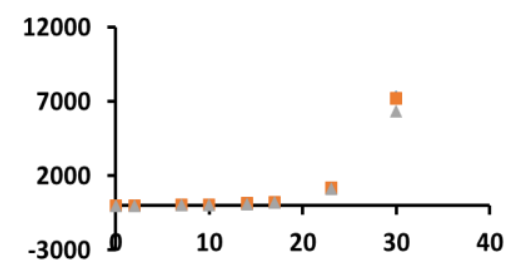
9 40 1 2 3 4 5 6 7 . 50 1 52 54 
57 Figure S3: Dissolved oxygen $\left(\mathrm{O}_{2}\right)$ concentrations in the water column from February 2013 to

September 2014. Data extracted from the Boknis Eck database: www.bokniseck.de/database.

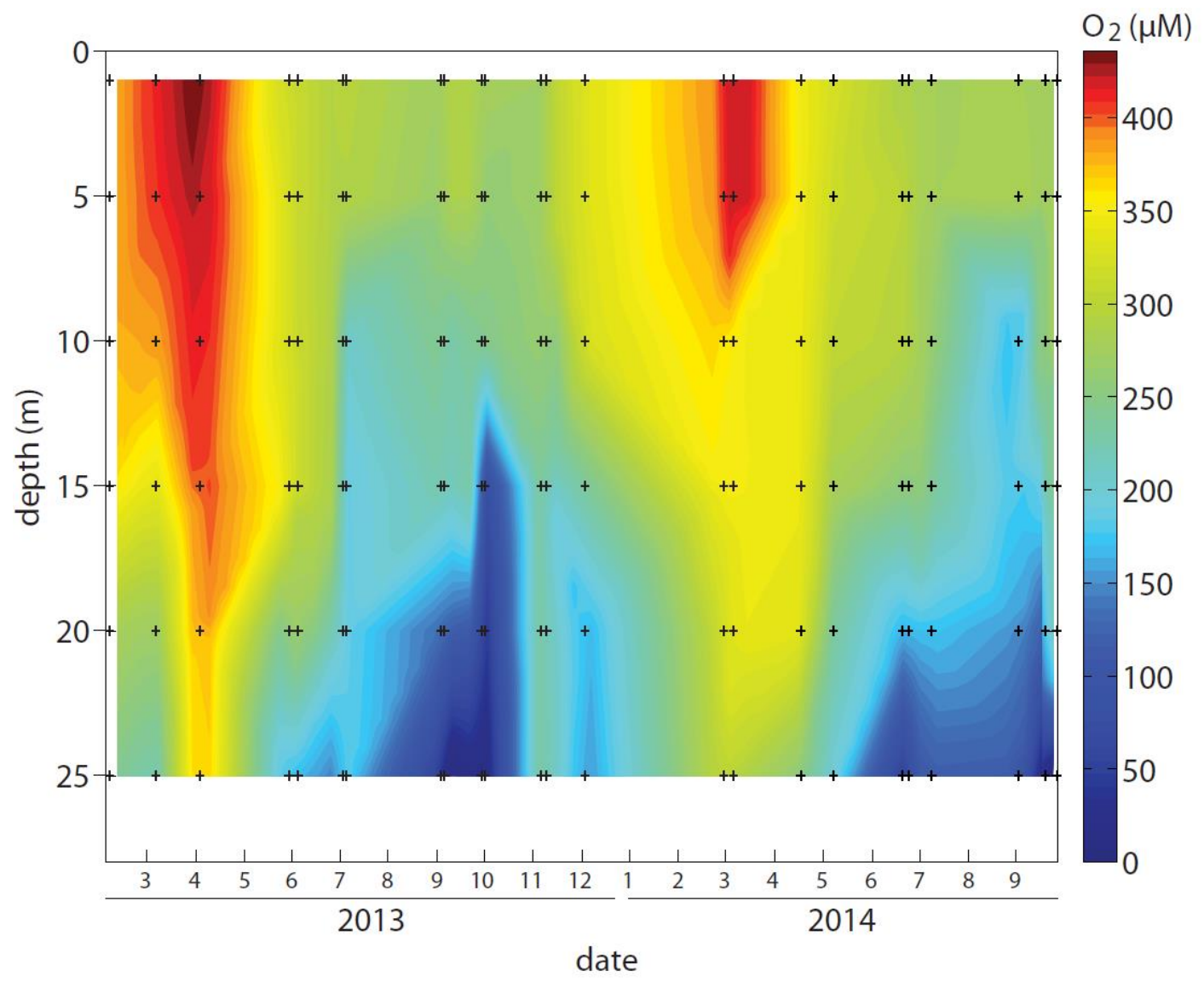

59

60 